\title{
Methods for ex Vitro Germination of Australian Terrestrial Orchids
}

\author{
Letitia Quay and Jen A. McComb \\ School of Biological and Environmental Sciences, Murdoch University, \\ Murdoch, WA 6150, Australia
}

\author{
Kingsley W. Dixon \\ Kings Park and Botanic Garden, West Perth, WA 6005, Australia \\ Additional index words. seed germination, mycorrhizal fungi, propagation, Caladenia \\ latifolia, Diuris magnifica
}

\begin{abstract}
Seeds of two Australian terrestrial orchid species (Caladenia latifolia R.Br. and Diuris magnifica D. Jones) were germinated in a potting mix of Allocasuarina fraseriana (Miq.) L. Johnson leaf mulch and perlite (1:1). The potting mix was irradiated (7 Gy for 14 hours), steam pasteurized ( $70 \mathrm{C}$ for 30 minutes) or nontreated, and inoculated with the appropriate mycorrhizal fungus for each species, a sterile red fungus (SRF), or both. Protocorm formation and green shoots were evident at 8 and 10 weeks, respectively, after seed sowing. The highest mean number of seedlings was 84 for $C$. latifolia and 234 for $D$. magnifica per $270-\mathrm{ml}$ container in pasteurized potting mix inoculated with mycorrhizal fungi and SRF. Shoots were longest after 20 weeks $(28 \mathrm{~mm}$ for $C$. latifolia and $52 \mathrm{~mm}$ for D. magnifica, respectively) in pasteurized potting mix inoculated with mycorrhizal fungi only. Germination was absent in control treatments without mycorrhizal fungi; with SRF only; or in nonsterile potting mix with mycorrhizal fungi, SRF, or both.
\end{abstract}

Western Australian is renowned for its wildflowers, particularly its terrestrial orchids. Many of these orchids are horticulturally desirable, but are more difficult to propagate than epiphytic species due to their greater dependence upon symbiotic (mycorrhizal) fungi for germination and development. $\mathrm{Na}-$ tive orchids have been successfully raised from seed using in vitro germination techniques, symbiotically (fungal assisted) and asymbiotically (without fungal assistance) (Arditti, 1982; Bunn, 1988; Dixon, 1987). However, these methods may not be economical for mass propagation or horticultural purposes.

Ex vitro germination (in situ seed sowing) of orchid seeds has been carried out by sowing around established parent plants, but little work has been done on seed germination in soil preinoculated with the appropriate mycorrhizal fungus (Dixon, 1987). The aim of this study was to develop ex vitro germination techniques for two species of terrestrial orchids, Caladenia latifolia R.Br. and Diuris magnifica D. Jones.

Plants of $C$. latifolia and D. magnifica located in the bushland of Kings Park, Perth, Western Australia, were cross-pollinated by hand to ensure production of abundant seed.

Received for publication 16Feb. 1995. Accepted for publication 28 Aug. 1995. This research was funded by Biotech International through the Cooperative Education for Enterprise Development program. The cost of publishing this paper was defrayed in part by the payment of page charges. Under postal regulations, this paper therefore must be hereby marked advertisement solely to indicate this fact.
Seed also was collected from C. latifolia plants that had set seed naturally. The ripe pods were placed in paper envelopes and allowed to dry before being stored in a desiccator at room temperature. The nonsterile potting mix was prepared from a 1 sheoak mulch (partially mulched leaves from around the base of Allocasuarina fraseriana trees located in Kings Park) : 1 perlite (v/v) mixture. Gamma-irradiated potting mix was prepared by mixing sheoak mulch (sterilized at 70 Gy for $14 \mathrm{~h}$ ) with perlite that had been autoclaved at $121 \mathrm{C}$ and $98 \mathrm{kPa}$ for $15 \mathrm{~min}$. The mixture was moistened with sterile distilled water. The study included mycorrhizal fungi from $C$. latifolia and D. magnifica and also a sterile red fungus (SRF) that acts as a biological control agent against various diseases and stimulates plant growth (Dewan and Sivasithamparam, 1988, 1989a, 1989b).

The appropriate mycorrhizal fungus for each orchid species was obtained from parent plants using the methods of Ramsay et al. (1986); its symbiotic potential was confirmed because it stimulated the germination of seeds of the appropriate orchid species (preliminary studies, in vitro). Mycorrhizal fungi were grown on potato dextrose agar in petri dishes and incubated at 20C. The mycelium and some agar of a 3-week-old culture of mycorrhizal fungus was roughly chopped using a scalpel, and applied to the soil at $6 \%(\mathrm{v} / \mathrm{v})$ using a 10$\mathrm{ml}$ sterile syringe. SRF was prepared by Biotech International and provided as mycelium on sterilized perlite, which was inoculated into the potting mix at $2 \%(\mathrm{v} / \mathrm{v})$ and distributed evenly within the mixture. Pasteurized potting mix was made by steam-pasteurizing the sheoak mulch at $70 \mathrm{C}$ for 30 min and adding perlite (autoclaved as before) and using sterile distilled water to moisten the mixture, if necessary. Fungal inoculation was carried out as described.

The potting mixes inoculated with mycorrhizal fungi were placed in $250-\mathrm{ml}$ polycarbonate tubs and incubated at $23 \mathrm{C}$ for 1 to 2 weeks before being dispersed into containers ready for seed sowing. Potting mix was placed into containers $(12 \times 7 \times 4 \mathrm{~cm})$, eight of which were fitted into a plastic tray. Each container represented one treatment replicate. Each container had at the bottom a 1-cm layer of noninoculated sheoak mulch and perlite (1:1), followed by a $2-\mathrm{cm}$ layer of sheoak mulch and perlite (1:1) inoculated with mycorrhizal fungus, SRF, or both; then the sand and seed mixture (described below) was sprinkled over it. This mixture was covered further with a 1$\mathrm{cm}$ layer of sheoak mulch containing orchid mycorrhizal fungus, SRF, or both. To produce the sand/seed mixture, seed from eight pods of C. latifolia or 10 pods of D. magnifica was mixed with $80 \mathrm{ml}$ white sand. Ten milliliters of this orchid seed/sand mixture was sprinkled evenly into each container.

Due to limited seed quantities available, gamma-irradiated potting mix was not used with $D$. magnifica, and no control was set up with $C$. latifolia, since the gamma irradiation would have killed all microorganisms, including mycorrhizal fungi, which are necessary for germination. Containers were placed under a fogging system (nonsterile) in a greenhouse at ambient temperatures $(\approx 8$ to $\approx 26 \mathrm{C}$ ) at the end of May, and monitored until the end of October. The number of shoots visible above the surface of the sheoak mulch (an estimate of germination) was scored periodically, and in the final assessment (after 20 weeks), shoot lengths were measured and the number of "elite" individuals (seedlings with shoot lengths $>50 \mathrm{~mm}$ for $C$. latifolia and $>100 \mathrm{~mm}$ for $D$. magnifica) scored. Statistical analysis of data was carried out using the SPSSX subprograms ANOVA and MANOVA (SPSS, Chicago).

No seedlings from either orchid species emerged in potting mixes that were not gammairradiated or pasteurized (data not shown). Germination of seeds of both species and the formation of protocorms were evident after 8 weeks, and healthy, green shoots were visible 10 weeks after seed sowing. The maximum mean number of seedlings of $C$. latifolia and D. magnifica per container after 20 weeks was 84 and 234, with seedlings having a mean shoot length of 28 and $52 \mathrm{~mm}$, respectively (Fig. 1A-D). The seedling production levels are a marked improvement on results from the in situ sowing methods currently used, in which seeds sown around a growing plant produce only a dozen or so plants (K.W.Dixon, personal communication).

Germination was absent in containers without mycorrhizal fungi, or where SRF was the only fungal inoculant. Germination also was absent in nonsterile potting mix with mycorrhizal fungus, SRF, or both.

More than twice the number of $C$. latifolia seedlings were produced in pasteurized potting mix than in gamma-irradiated potting mix (Fig. 1A), although there was little effect on 

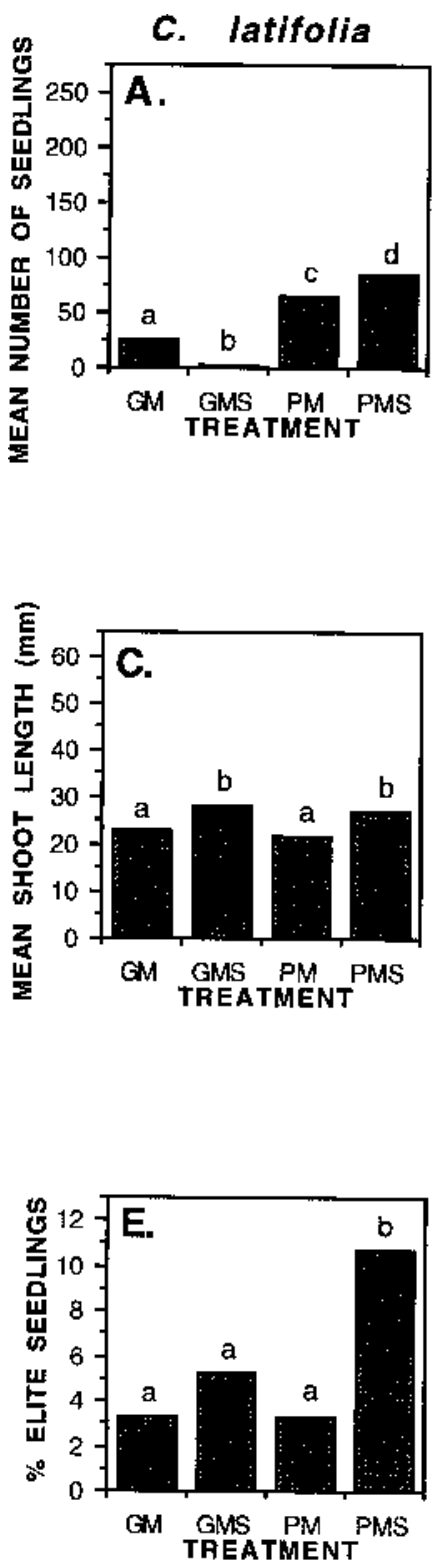

Fig. 1. Effect of potting mix and fungal inoculants on ex vitro germination of $C$. latifolia and D. magnifica 20 weeks after seed sowing: $(\mathbf{A}, \mathbf{B})$ mean number of seedlings per container; $(\mathbf{C}, \mathbf{D})$ mean aboveground shoot length; (E, F) proportion of "elite" seedlings with shoot lengths $>50 \mathrm{~mm}$ for C. latifolia and $>100$ mm for D. magnifica. GM: gamma-irradiated potting mix with mycorrhizal fungus; GMS: gammairradiated potting mix with mycorrhizal fungus and sterile red fungus (SRF); PM: pasteurized potting mix with mycorrhizal fungus; PMS: pasteurized potting mix with mycorrhizal fungus and SRF. Means taken from seven to eight replicate containers. Mean separation within treatments was determined by single degree-of-freedom contrasts $(P<0.001)$.

seedling development (Fig. 1C). The addition of mycorrhizal fungi and SRF to the pasteurized potting mix produced the most seedlings (Fig. 1A) and highest proportion of elite individuals (Fig. 1E) of C. latifolia.

Only pasteurized potting mix was used for D. magnifica and there was no significant increase $(P>0.05)$ in the number of seedlings produced in the SRF plus mycorrhizal fungus treatments (Fig. 1B). Seedlings growing in
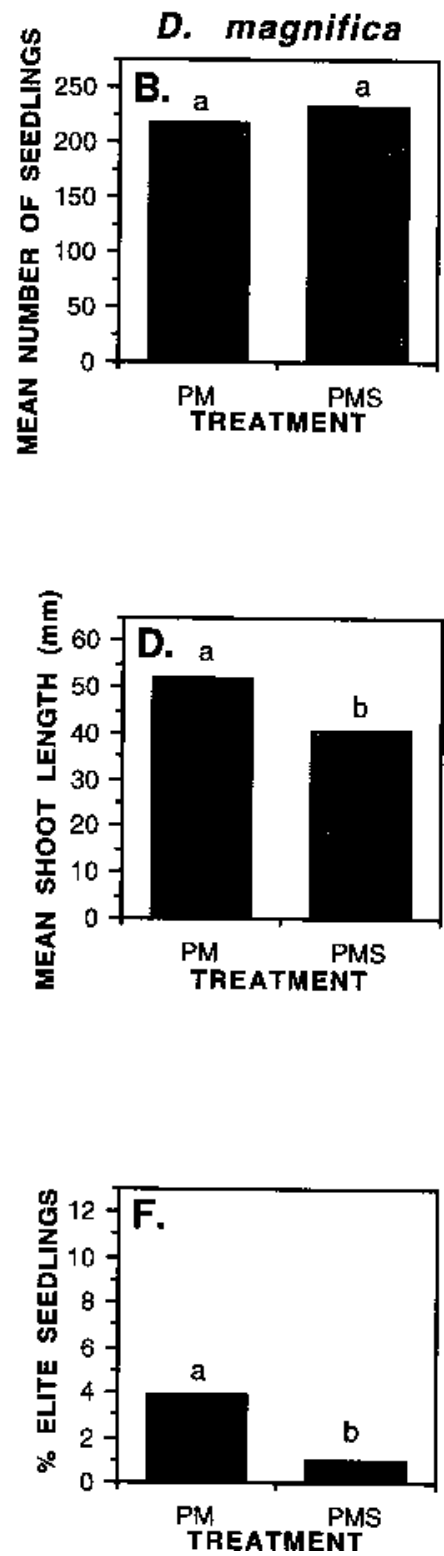

pasteurized potting mix with only mycorrhizal fungus had longer shoots and a higher proportion of elite individuals $(P<0.001)$ (Fig. $1 \mathrm{D}$ and F) than those with mycorrhizal fungus and SRF.

This experiment suggested that SRF enhanced germination in $C$. latifolia, but had a slight negative effect on $D$. magnifica in pasteurized soil. The way in which SRF interacts is unclear.
In gamma-irradiated soil, seedling emergence for $C$. latifolia was higher with mycorrhiza only than with mycorrhiza and SRF. This result is also consistent with Dewan and Sivasithamparam (1988), who found that SRF conferred greater benefits to plants in nonsterile soil than in sterile soil. Gamma irradiation alters soil properties and causes release of substances that may be either beneficial or toxic to plants and microorganisms alike (Smith and Smith, 1981).

The decrease in germination when SRF was added to gamma-irradiated soil or to mycorrhizal fungus is difficult to explain. Further in vitro experiments should be carried out to investigate the interactions between the mycorrhizal fungus and SRF and the effects on orchid seed germination.

The ex vitro germination technique detailed here can be used for commercial production of terrestrial orchid seedlings. Although lower percentages of seed germination are obtained than from the in vitro techniques, in vitro seedlings encounter major problems during their transfer to soil and frequently do not establish well or do not produce tubers. Our seedlings germinated in preinoculated potting mix required about the same period of time for germination, but plants of the same age were more robust than those in vitro.

\section{Literature Cited}

Arditti, J. 1982. Orchid seed germination and seedling culture-A manual, p. 242-370. In: J. Arditti (ed.). Orchid biology: Reviews and perspectives II. Cornell Univ. Press, London.

Bunn, E. 1988. Seed and tissue culture of Australian Orchidaceae, p. 55-71. In: N.D. Stockton (ed.). Papers presented at a workshop on Australian orchids. Murdoch Univ. Press, Perth.

Dewan, M.M. and K. Sivasithamparam. 1988. A plant-growth promoting sterile red fungus from wheat and ryegrass roots with potential for suppressing take-all. Trans. Brit. Mycol. Soc. 91:687-692.

Dewan, M.M. and K. Sivasithamparam. 1989a. Growth promotion of rotation crop species by a sterile red fungus from wheat and effect of soil temperature and water potential on its suppression of take-all. Mycol. Res. 93:156-160.

Dewan, M.M. and K. Sivasithamparam. 1989b. Behaviour of a plant-growth-promoting sterile red fungus on agar and roots of ryegrass and wheat. Mycol. Res. 93:161-166.

Dixon, K.W. 1987. Raising terrestrial orchids from seed, p. 47-54. In: W.K. Harris (ed.). Modern orchid growing for pleasure and profit. Orchid Club of South Australia, Adelaide.

Ramsay, R.R., K.W. Dixon, and K. Sivasithamparam. 1986. Patterns of infection and endophytes associated with Western Australian orchids. Lindleyana 1:203-214.

Smith, F.A. and S.E. Smith. 1981. Mycorrhizal infection and growth of Trifolium subterraneum: Use of sterilized soil as a control treatment. New Phytol. 88:299-309. 